Article

\title{
Sustainable Replacement of Aging Drinking Water Lines Using Horizontal Directional Drilling Technology
}

\author{
Samuel T. Ariaratnam ${ }^{1}$, Noel Guercio ${ }^{2}$ \\ 1 School of Sustainable Engineering \& the Built Environment, Arizona State \\ University, Tempe, AZ 85281, USA \\ 2 Stantec Consulting Services, Inc., New York, NY 10017, USA \\ * Correspondence: Samuel T. Ariaratnam, Email: ariaratnam@asu.edu; \\ Tel.: +1-480-965-7399.
}

\begin{abstract}
Background: Due to deterioration from aging, the City of Yuma, Arizona undertook the replacement of approximately 5800 L.F. (1767 m) of existing aging and undersized asbestos cement water lines in the vicinity of the downtown core to reduce maintenance and repairs and improve water service levels. Installed between 1938 and 1940, six line segments of existing 2-inch $(50 \mathrm{~mm})$ to 6 -inch $(150 \mathrm{~mm})$ asbestos cement water lines were replaced by 6-inch $(150 \mathrm{~mm})$ diameter PVC pipe.
\end{abstract}

Methods: To study advantages and disadvantages of traditional open-cut construction compared to Horizontal Directional Drilling (HDD), the City separated the project into approximately 2000 L.F. (609 m) of HDD and 3800 L.F. (1158 m) of open-cut. Analyzing the same project provided an opportunity to study a true head-to-head comparison of the two methods. PVC C900 DR18 was installed using open-cut, while Fusible PVC (FPVC) DR18 was installed by HDD. Data was collected in the field over a twomonth period with factors analyzed including comparison of: (1) environmental impacts; (2) traffic impacts; and (3) productivity.

Results: The results found HDD to have inherent advantages in all three areas when compared to traditional open-cut. The HDD option emitted approximately $23 \%$ of airborne emissions compared to open cut. Traffic

\section{G Open Access}

Received: 31 October 2019

Accepted: 29 May 2020

Published: 04 June 2020

Copyright $₫ 2020$ by the author(s). Licensee Hapres, London, United Kingdom. This is an open access article distributed under the terms and conditions of Creative Commons Attribution 4.0 International License. was restricted in the sections involving open-cut construction, while the HDD sections had continuous traffic flow due to the closure of only one lane. HDD achieved an average productivity of 1.91 L.F./min $(0.58 \mathrm{~m} / \mathrm{min})$ compared to traditional open-cut, which achieved an average productivity of 0.43 L.F./min $(0.13 \mathrm{~m} / \mathrm{min})$. This translates to HDD achieving a production rate greater than four times that of open-cut.

Conclusions: The adoption of trenchless technologies such as HDD will continue to increase as municipalities turn to sustainable solutions for replacing and/or rehabilitating their existing water pipe line infrastructure. HDD has proven to be superior to open-cut construction in environmental, traffic control and productivity. 
KEYWORDS: drinking water; pipeline renewal; sustainable development; trenchless technology

\section{ABBREVIATIONS}

HDD, Horizontal Directional Drilling; Fusible PVC pipe, FPVC pipe

\section{INTRODUCTION}

Located in the southwestern corner of Arizona bordering California, Yuma (population 93,000) serves as a halfway point between Phoenix, AZ and San Diego, CA. The City's Engineering Department engaged in a project to replace an aging asbestos cement drinking water system in the downtown area in February 2016. The Downtown Waterline Replacement project involved replacing their aging 4-inch $(100 \mathrm{~mm})$ and 6-inch $(150 \mathrm{~mm})$ asbestos cement drinking waterlines with 6-inch $(150 \mathrm{~mm}) \mathrm{PVC}$ pipes. The existing pipes were installed between 1938 and 1940 and had far exceeded their 50-year design life. In keeping with principles of sustainable infrastructure development, preference was given to replacement practices that would make the water infrastructure adhere to social, environmental and economic pillars of sustainability. For water utilities, sustainability is about creating reliable, consistent infrastructure that can be managed, maintained and upgraded without destroying the environment or bankrupting users. The City initially explored trenchless pipe replacement, Horizontal Directional Drilling (HDD), and traditional open-cut as possible construction options. The trenchless pipe replacement option was eliminated as a result of concerns with bursting existing asbestos cement pipe. Subsequently, HDD and open-cut were deemed the remaining options. Environmental impacts (environmental), traffic impacts (social), and productivity (economical) comparing traditional open-cut construction and HDD were evaluated to assess the advantages and disadvantages of each method using data collected during installation. Additionally, samples were obtained to evaluate water quality (environmental) before and after pipe replacement.

During the design stage, the replacement project was divided into two separate design packages for the purpose of comparing Horizontal Directional Drilling (HDD) versus traditional open-cut construction. This project provided a head-to-head comparison of the two methods being that it is one project in the same local environment. A total of 3800 L.F. (1160 m) of 6-inch (150 mm) C900, CL 235 DR18 fully restrained PVC water pipe using traditional open-cut construction and 2000 L.F. $(600 \mathrm{~m})$ of 6-inch (150 mm) C900, CL 235 DR18 fully restrained FPVC water pipe using HDD were installed. Figure 1 illustrates a plan showing the waterline replacement sections, while a summary of the design lengths of the two techniques are presented in Table 1. 


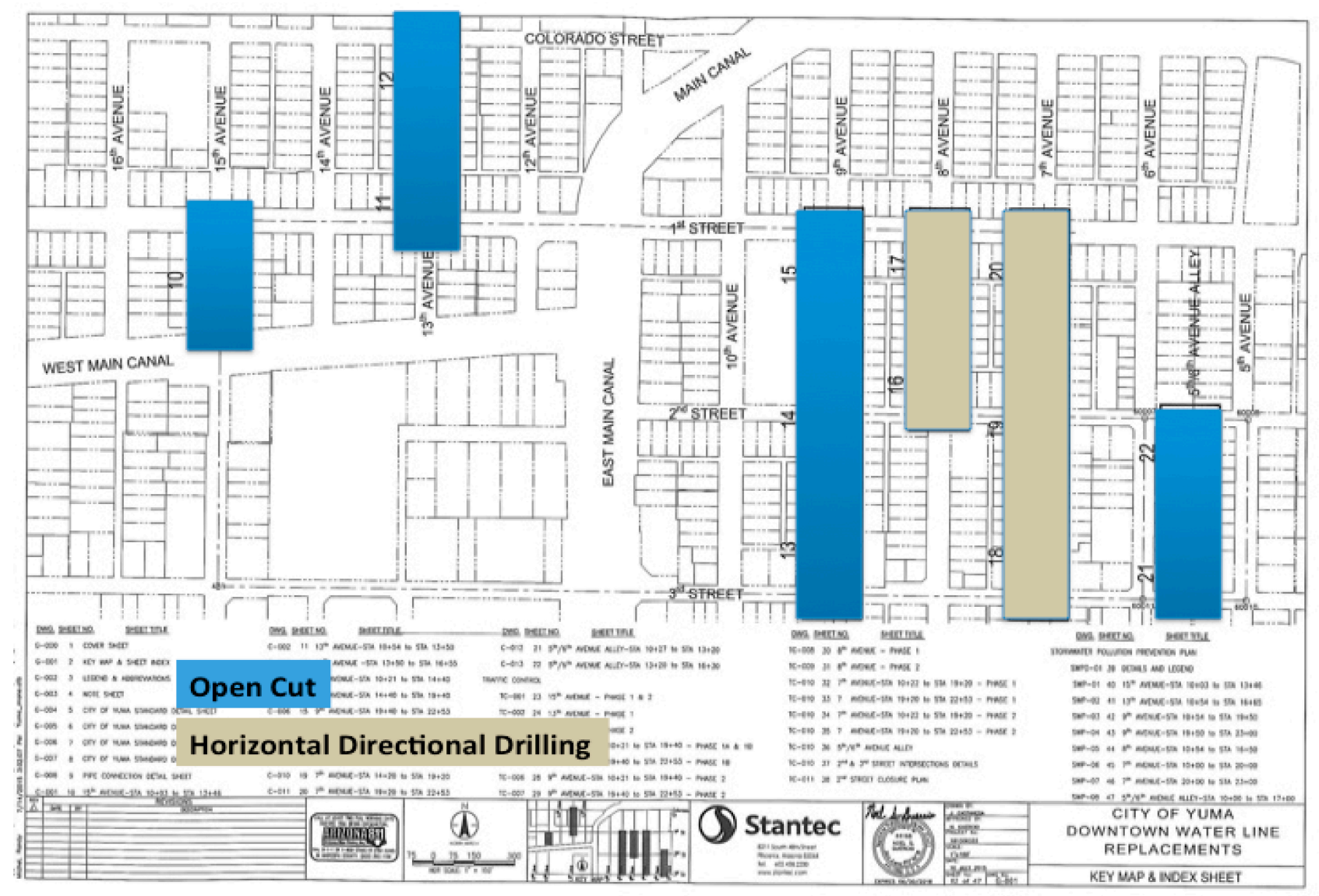

Figure 1. Water line replacement sections in downtown Yuma, AZ.

Table 1. Summary of replacement locations and design lengths.

\begin{tabular}{|c|c|c|c|}
\hline Installation Method & \multicolumn{3}{c|}{ Location } \\
\hline \multirow{2}{*}{ Horizontal Directional Drilling } & Phase I & 8th Avenue & 700 L.F. $(213 \mathrm{~m})$ \\
\cline { 2 - 4 } & Phase II & 7th Avenue & 1300 L.F. (396 m) \\
\hline \multirow{3}{*}{ Open-Cut } & Phase III & 5th/6th Avenue Alley & 675 L.F. (205 m) \\
\cline { 2 - 4 } & Phase IV & 9th Avenue & 2000 L.F. (610 m) \\
\cline { 2 - 4 } & Phase V & 13th Avenue & 725 L.F. (221 m) \\
\cline { 2 - 4 } & Phase VI & 15th Avenue & 400 L.F. (122 m) \\
\hline
\end{tabular}

\section{MATERIALS AND METHODS}

Data collection involved collecting on-site real time data on equipment usage and activity characteristics over a two-month period between February and March 2016. A dedicated researcher was on-site to collect data on the studied open-cut and HDD sections. This included environmental impacts, traffic impacts, and productivity. Furthermore, information on all specific equipment used on the project including model year, engine hours, load factor, horsepower, and percent utilization was carefully recorded. Calculation of emissions was based on specific equipment and respective activities to provide actual emissions and productivities. Equipment information for the open-cut and HDD installations is shown in the following section. 
The open-cut construction portion of the project analyzed in this study involved water line replacements at three locations: (1) 9th Avenue (April 4-6); (2) 13th Avenue (March 17); and (3) 15th Avenue (March 16). Table 2 presents information on the specific equipment used on each of the three open-cut sections. The Case 590 Super L excavator used in the project is shown in Figure 2.

Table 2. Details of equipment used for open-cut installation.

\begin{tabular}{|l|l|l|l|}
\hline Name & Model & Power & Activities \\
\hline Excavator & 2012 Case 590 Super L (4T-390) & $95 \mathrm{hp}$ & $\begin{array}{l}\text { 1. Excavation of trench } \\
\text { 2. Backfilling of trench } \\
\text { 3. Lifting of pipe and layout }\end{array}$ \\
\hline Hand Compactor & 2014 Lancin 196CC & $5.5 \mathrm{hp}$ & Compaction of backfill \\
\hline Truck & 2015 Dodge Ram 3500 & $383 \mathrm{hp}$ & Transport \\
\hline Truck & 2015 Form F350 & $385 \mathrm{hp}$ & Transport \\
\hline Water Truck & 2002 Chevrolet C6500 & $207 \mathrm{hp}$ & Dust control \\
\hline
\end{tabular}

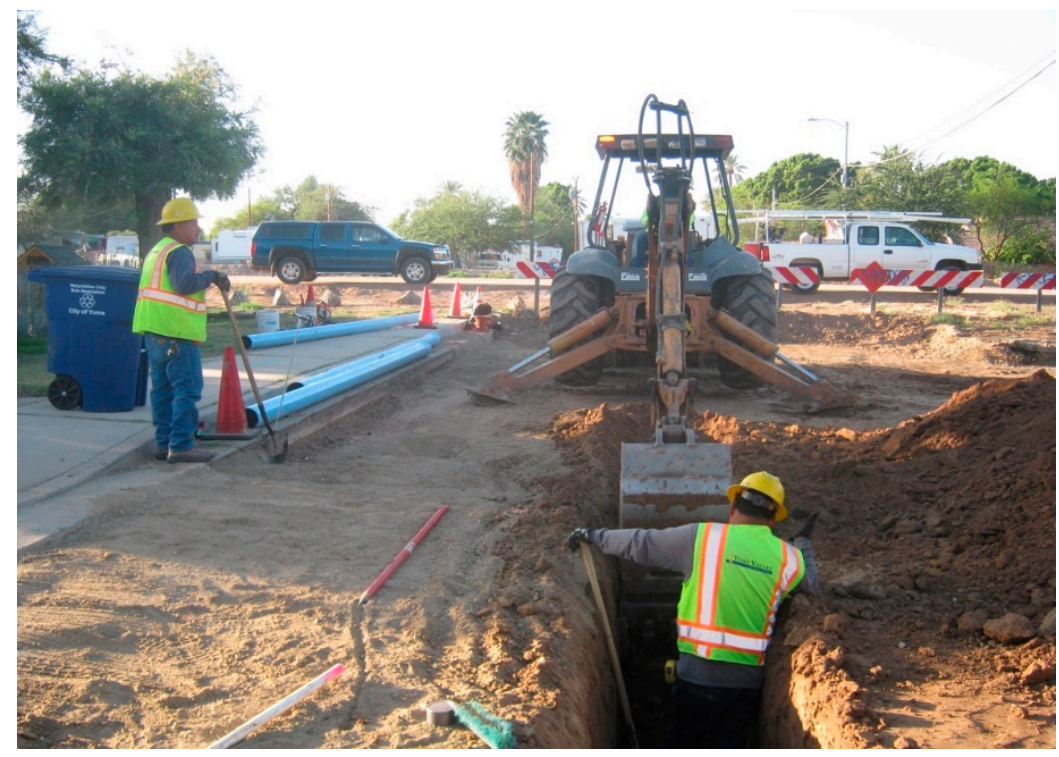

Figure 2. Case 590 Super L excavator used on project.

The HDD portion of the project analyzed involved water line replacements at three locations: (1) 8th Avenue between 1st and 2nd Streets (February 9-10); (2) 7th Avenue between 1st and 2nd Streets (February 11); and (3) 7th Avenue between 2nd and 3rd Streets (February 12). HDD is a trenchless technology capable of installing a variety of underground utilities including water, wastewater, electrical, telecommunication, cable, and energy pipelines. Utilities with diameters of 2-inches $(50 \mathrm{~mm})$ to 65 -inches $(1.65 \mathrm{~m})$ have been installed with the record length of installation being 17,060 L.F. $(5.2 \mathrm{~km})$. The process involves an initial pilot bore that follows the prescribed design alignment as shown in Figure 3(a). This is followed by a backreaming/pipe installation process in which a reamer is used to enlarge the initial pilot 
bore to a size of 1.5 times the outside diameter of the product pipe being installed as shown in Figure 3(b). A bentonite-based drilling fluid mixture composed of approximately $97 \%$ water is used to facilitate product installation. Installations with surface access are generally installed using a walkover locating systems to track the progress of the drill bit during the pilot bore installation via an electromagnetic signal. For installations beneath waterbodies or with limited surface access, a wireline system such as employed in petroleum exploration is used for locating the drill head. Further information on the state-of-the-art in HDD can be found in [1]. Table 3 presents the information on the equipment used on each of the three sections. The Vermeer D24 $\times 40 \mathrm{~A}$ rig used in the project is shown in Figure 4.

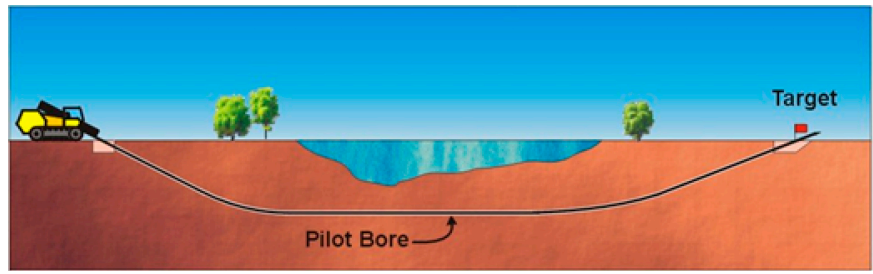

(a)

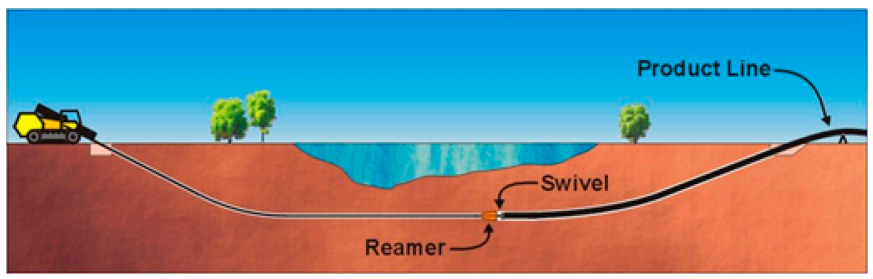

(b)

Figure 3. (a). Pilot Bore Installation. (b). Backreaming and Product Installation.

Table 3. Details of equipment used for HDD installation.

\begin{tabular}{|l|l|l|l|}
\hline Name & Model & Power & Activities \\
\hline HDD Rig & 2000 Vermeer D24 $\times 40 \mathrm{~A}$ & $125 \mathrm{hp}$ & $\begin{array}{l}\text { 1. Pilot bore } \\
2 . \quad \text { Pre-reaming } \\
3 . \quad \text { Pullback and Pipe Installation }\end{array}$ \\
\hline Excavator & & & Excavation of entry \& exit pits \\
\hline Vacuum Truck & Vacmaster System 4000 & $95 \mathrm{hp}$ & Potholing existing utilities \\
\hline Fluid Mixing System & Vermeer 2000 Gallon Mud Mixer & $16 \mathrm{hp}$ & Mixing of drilling fluid \\
\hline Truck & 2008 Ford F650 & $330 \mathrm{hp}$ & Transport of vacuum equipment \\
\hline Truck & 1993 Kenworth T800 & $450 \mathrm{hp}$ & Transport of mixing system \\
\hline Water Truck & 2002 Chevrolet C6500 & $207 \mathrm{hp}$ & Dust control \\
\hline Truck & Kenworth W900 & $600 \mathrm{hp}$ & Transport of HDD rig \\
\hline
\end{tabular}

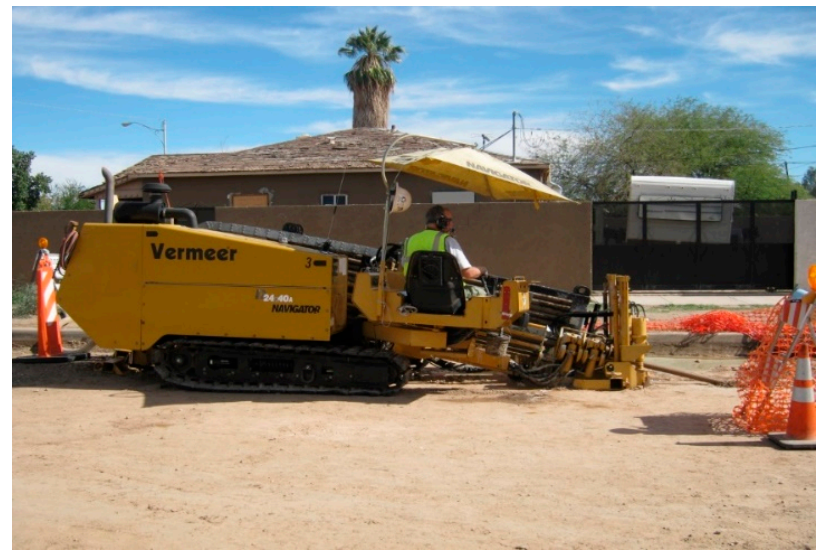

Figure 4. Vermeer D24 × 40A HDD rig used on project. 


\section{RESULTS}

\section{Environmental Calculations of Airborne Emissions}

An emission calculator tool was developed in MS Excel using Visual Basic coding. E-Calc ${ }^{\mathrm{TM}}$ estimates emissions (i.e., hydrocarbons (HC); carbon monoxide (CO); nitrogen oxide $\left(\mathrm{NO}_{\mathrm{x}}\right)$; particulate matter $(\mathrm{PM})$; carbon dioxide $\left(\mathrm{CO}_{2}\right)$; and sulfur oxide $\left(\mathrm{SO}_{\mathrm{x}}\right)$ ) from underground utility projects based on EPA-approved methodology [2]. A comprehensive description of E-Calc ${ }^{\mathrm{TM}}$ can be found in [3]. Required input data can be obtained from daily progress reports or productivity estimates, while equipment-specific information should be acquired from the contractor. Non-road equipment data include: power; model year; engine technology; useful hours and cumulative hours to date; fuel characteristics such as type and sulfur content; and activity characteristics such as representative equipment cycle, power used, and hours of use. The data required to calculate emissions generated from on-road transportation equipment include: model year; gross vehicle weight; mileage; fuel characteristics such as type and sulfur content; and activity characteristics such as altitude of operation, number of trips, one way distance, and return distance.

As with any software tool, the accuracy of output information depends on the accuracy of the input data. The calculator is a proven tool intended for contractors, engineers, and owners to obtain an estimate of the environmental impact of their proposed underground utility project [4,5]. The tool provides a comparison of emissions generated from two possible installation methods with default information available for four typical utility construction methods: (1) horizontal directional drilling; (2) trenchless pipe replacement; (3) trenching; and (4) traditional open-cut. It should be noted that the tool is portable and can be applied to any construction process that incorporates machinery and equipment such as water main replacement technologies studied in this research. This software tool has been used for evaluating numerous trenchless technology options [3-5]. Figure 5 illustrates a sample output emissions calculation screen for HDD on this project.

The emission factor is the basic tool for estimating emissions. It is usually expressed as the weight of pollutant emitted divided by a unit weight, volume, distance, or duration of the activity emitting the pollutant. The emission factors are used to determine the emissions from equipment or machineries that burn fuel. The general equation provided in document $\mathrm{EPA} / 454 / \mathrm{R}-95 / 015$ [2] is:

$$
\mathrm{E}=\mathrm{A} \times \mathrm{EF} \times\left[1-\left(\frac{\mathrm{ER}}{100}\right)\right]
$$

Where;

$\mathrm{E}=$ emissions

$\mathrm{A}=$ activity rate 
$\mathrm{EF}=$ uncontrolled emission factor

$\mathrm{ER}=$ overall emission reduction efficiency, \%

(ER is the product of the control device destruction or removal efficiency and the capture efficiency of the control system).

The activity rate is a function of the specific activity under consideration. The activity rate determination is based on the emission factor, which was calculated based on the test data ratings. If the emission factor is expressed as the weight of pollutant released for a volume of fuel consumed by the activity, the activity rate should be the measurement of the volume of fuel consumed by that activity [5].

In the case of emission factors expressed in terms of $\mathrm{g} / \mathrm{hp}$-hr, the activity needs to be measured in terms of power (hp) consumed and duration (hr.) of the activity that emits the pollutants. If the emission factor is expressed in terms of $\mathrm{g} / \mathrm{gal}$, then the activity rate should be the measure of gallons of fuel burned. An example of the summary screen from eCalc ${ }^{\mathrm{TM}}$ is shown in Figure 6.

A comparison of airborne emissions from the open-cut and HDD installations is illustrated in Figure 7 and shows the inherent environmental benefits of the HDD option. Converting emitted emissions to a normalize value shows HDD to have produced less than a third of $\mathrm{CO}_{2}$ emissions compared to traditional open-cut. Overall, the HDD option emitted approximately $23 \%$ airborne emissions compared to open-cut.

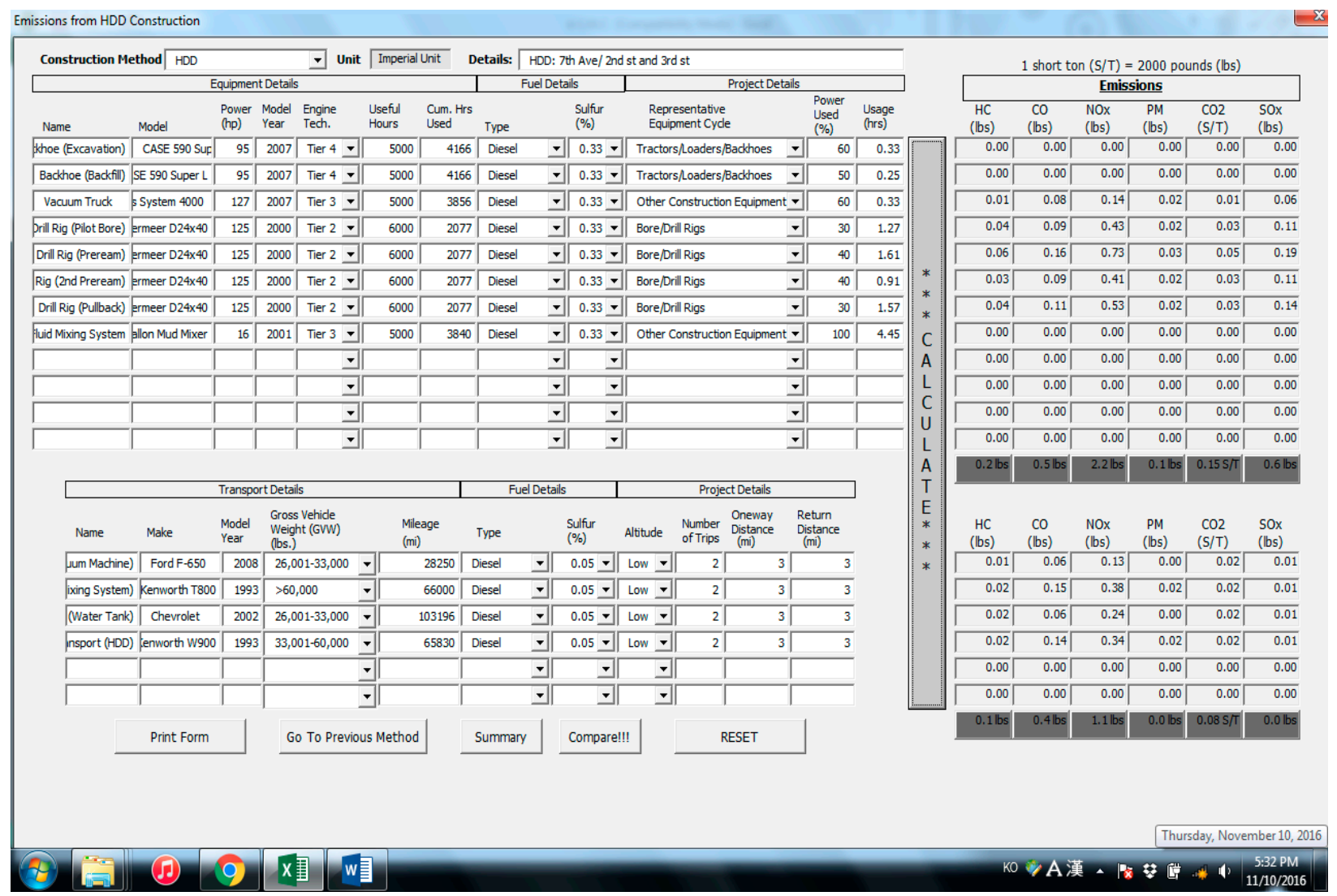

Figure 5. Sample HDD output emissions calculation screen [6]. 


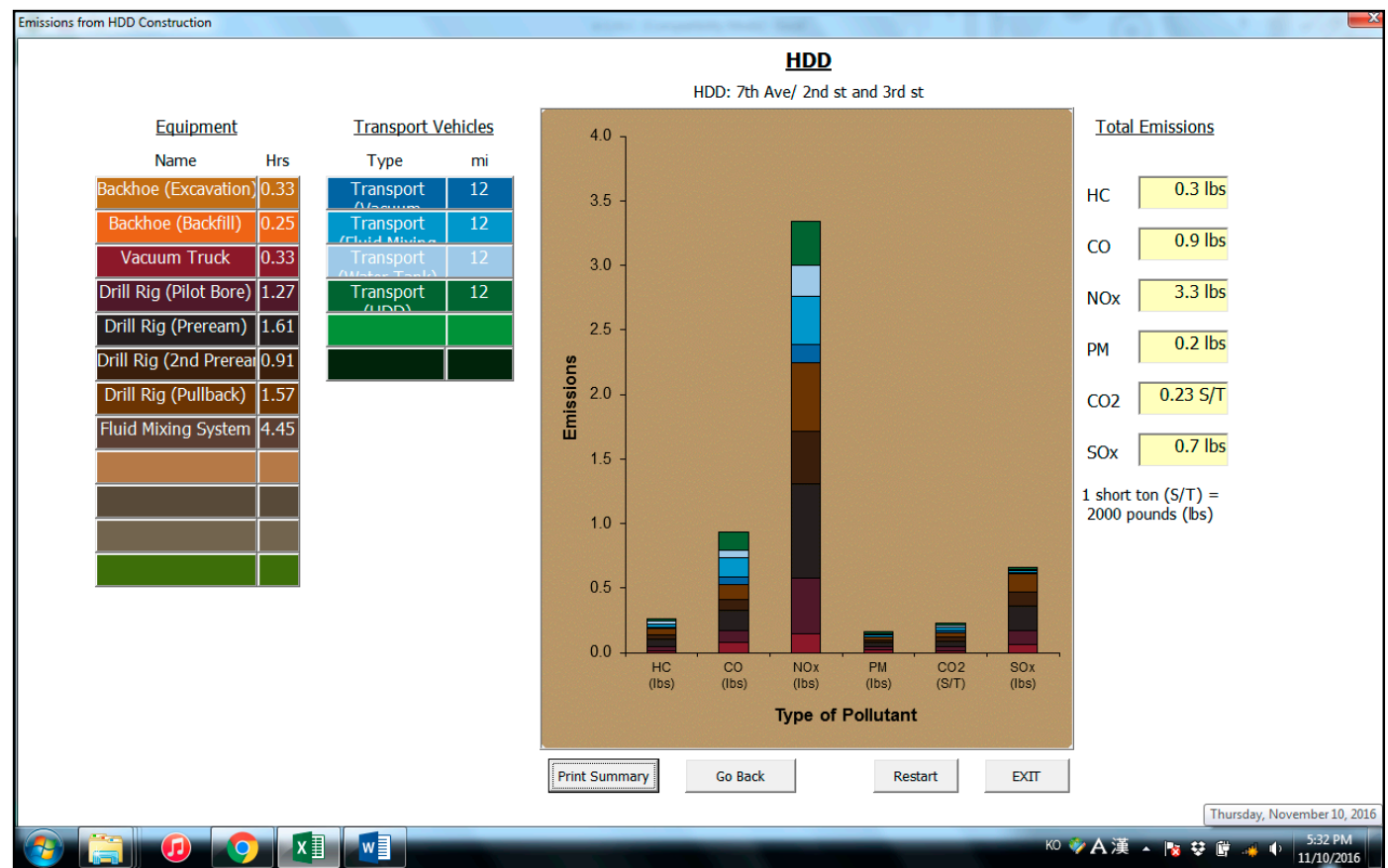

Figure 6. Sample HDD emissions summary screen [6].

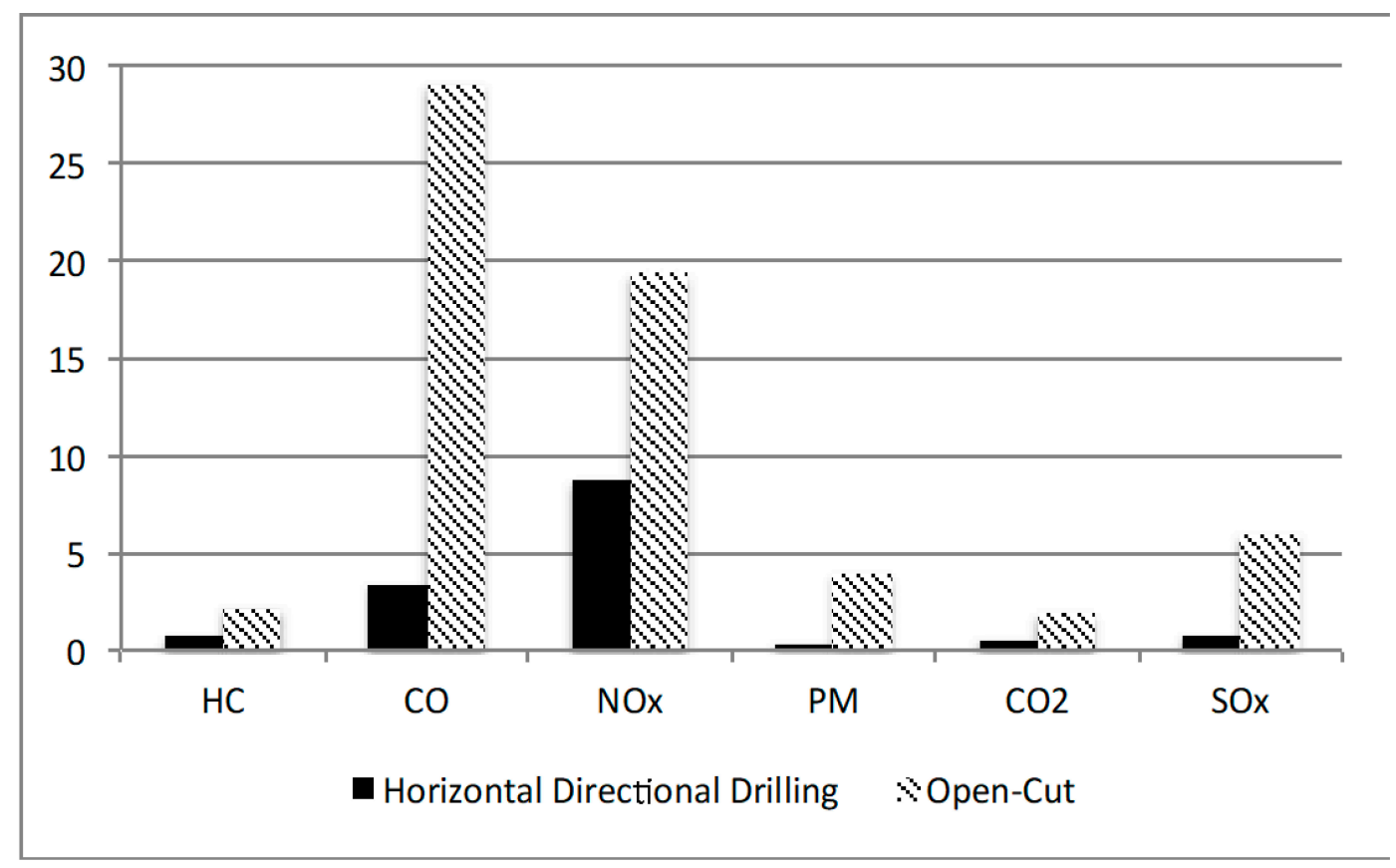

Figure 7. Comparison of emissions $\left(\times 10^{-3}\right)[6]$.

\section{Traffic Impacts}

Numerous researchers have cited reduction in traffic impacts as a major benefit of adopting trenchless technologies such as HDD [7-9]. Being in a residential neighborhood near the downtown core, it was important to minimize traffic impacts and inconvenience to the local residents. The sections with installations using traditional open-cut construction involved closure of the entire street to traffic as shown in Figure 8. Conversely, only half of the street was closed during the HDD installations 
as shown in Figure 9, thus enabling traffic flow. This further demonstrates an advantage of utilizing trenchless methods, particularly in urban areas. In this project, the City of Yuma planned on replacing the entire deteriorated pavement. Generally, only minimal sections of pavement at the entry and exit pits require replacement when employing HDD.

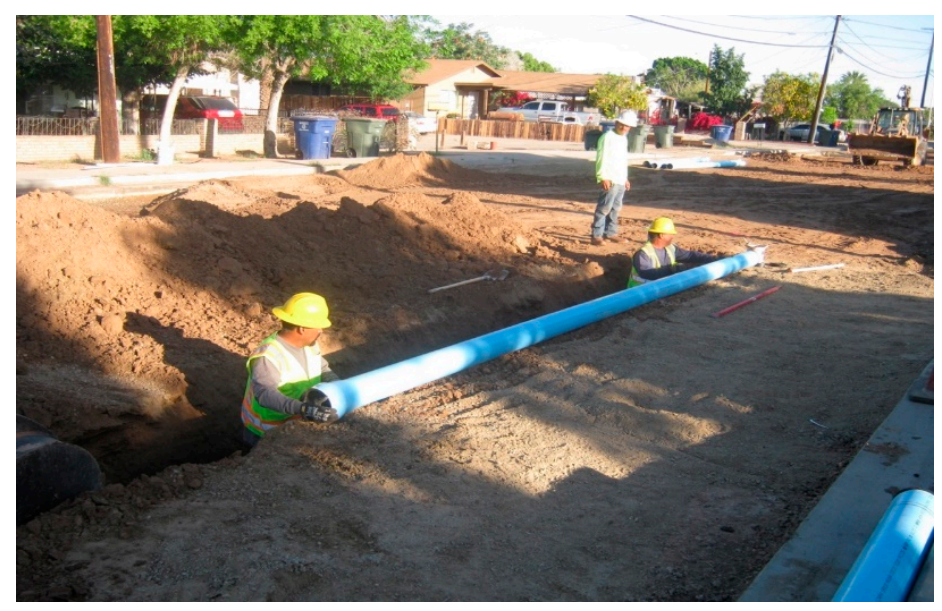

Figure 8. Closure of entire street for open-cut.

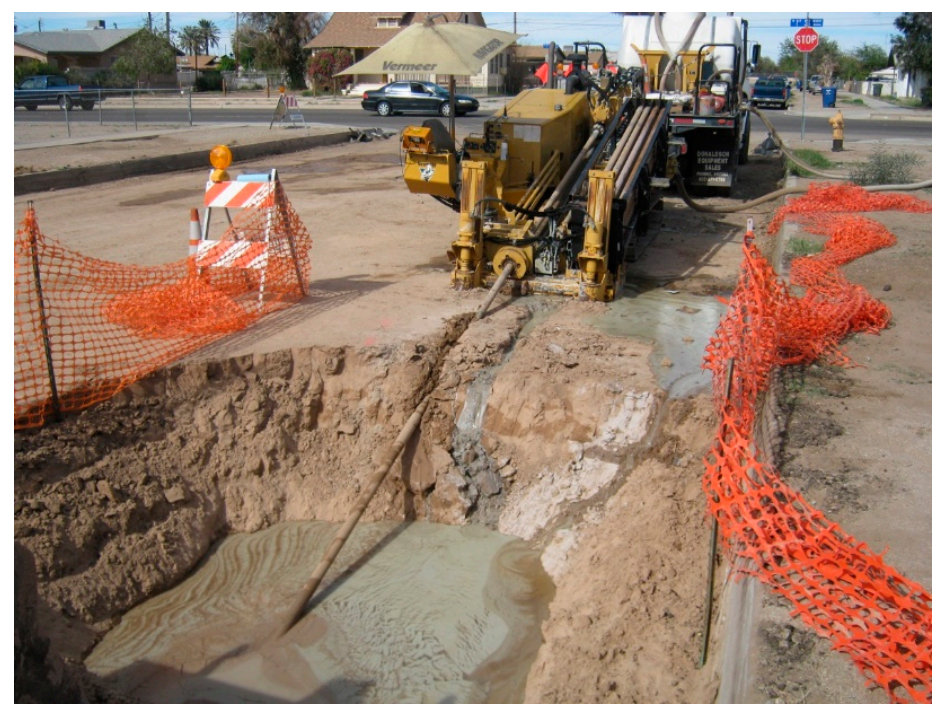

Figure 9. Partial street closure for HDD installation.

\section{Productivity Analysis}

Productivity data was collected onsite for both the HDD and open-cut installations. All activities were timed by a stopwatch to record the various tasks associated with both installation methods. All values were normalized to productivity shown in linear feet $(\mathrm{m})$ per minute (L.F. (m)/min) to reflect varying installation lengths. As shown in Table 4, HDD achieved an average productivity of 1.91 L.F./min $(0.58 \mathrm{~m} / \mathrm{min})$ compared to traditional open-cut, which achieved an average productivity of 0.43 L.F./min $(0.13 \mathrm{~m} / \mathrm{min})$. The results revealed HDD to achieve productivity greater than four times that of open-cut. It should be noted that productivity did not consider surface replacement such as paving or 
other tasks. The City of Yuma decided to repave all of the streets regardless of installation method and thus restoration was not considered in the analysis. If considered, significantly more time would have been dedicated to surface restoration with the open-cut method. Productivity was measured as the time from excavation to final installation of the PVC pipe. In the case of open-cut, this included compaction of the backfill material.

As previously stated, HDD was able to achieve more than four times the productivity rate as traditional open-cut. This may be attributed to the ability of HDD to navigate horizontally once the drill rod is inserted into the ground. Improved accuracy of the tracking equipment and tooling enables for more accurate installation, thereby reducing the likelihood of striking an existing buried utility. Furthermore, the HDD contractor was required to pothole and confirm the depth of all existing utilities that crossed the path of the PVC pipe installation.

Table 4. Productivity comparison.

\begin{tabular}{|c|c|c|c|c|c|}
\hline Installation Method & Location & $\begin{array}{c}\text { Installation Length } \\
\text { Monitored }\end{array}$ & $\begin{array}{l}\text { Time for Completion } \\
\text { (minutes) }\end{array}$ & Date & $\begin{array}{c}\text { Productivity } \\
\text { (L.F./min) }\end{array}$ \\
\hline \multirow{3}{*}{$\begin{array}{c}\text { Horizontal } \\
\text { Directional Drilling }\end{array}$} & 8th Avenue & 520 L.F. (158 m) & 242 & Feb 8-9 & 2.15 \\
\hline & 7th Avenue & 1060 L.F. (323 m) & 639 & Feb 10-11 & 1.66 \\
\hline & \multicolumn{4}{|r|}{ AVERAGE } & $1.91(0.58 \mathrm{~m})$ \\
\hline \multirow{4}{*}{ Open-Cut } & 15th Avenue & 70 L.F. (21 m) & 321 & Mar 16 & 0.22 \\
\hline & 13th Avenue & 175 L.F. (53 m) & 385 & Mar 17 & 0.45 \\
\hline & 9th Avenue & 700 L.F. (213 m) & 1,103 & Apr 4-6 & 0.63 \\
\hline & \multicolumn{4}{|r|}{ AVERAGE } & $0.43(0.13 \mathrm{~m})$ \\
\hline
\end{tabular}

\section{Water Quality Sampling}

Water samples were taken from nine different fire hydrants before and after water line replacement and tested for presence of chlorine and $E$. coli in a laboratory. According to the Centers for Disease Control and Prevention, chlorine levels up to 4 milligrams per liter $(\mathrm{mg} / \mathrm{L})$ are considered safe in drinking water. The Environmental Protection Agency recommends $E$. coli levels of $0 \mathrm{CFU} / 100 \mathrm{~mL}$ as the only acceptable level for human consumption. The samples were initially taken on February 10, 2016 and then on July 29, 2016 once the system had been in operation for a few months. The object of the water quality sampling was to evaluate if any improvements in water quality occurred after installation of the new pipes. As shown in Figure 10, there was a slight to moderate reduction in chlorine content after installation of the new water lines. E. coli was present in five samples (hydrants) taken prior to replacement as illustrated in Figure 11. As expected, post installation samples did not reveal any E. coli present. Overall, testing of these water samples further 
demonstrated the importance of replacing aging drinking water lines to improve human health quality in a community.

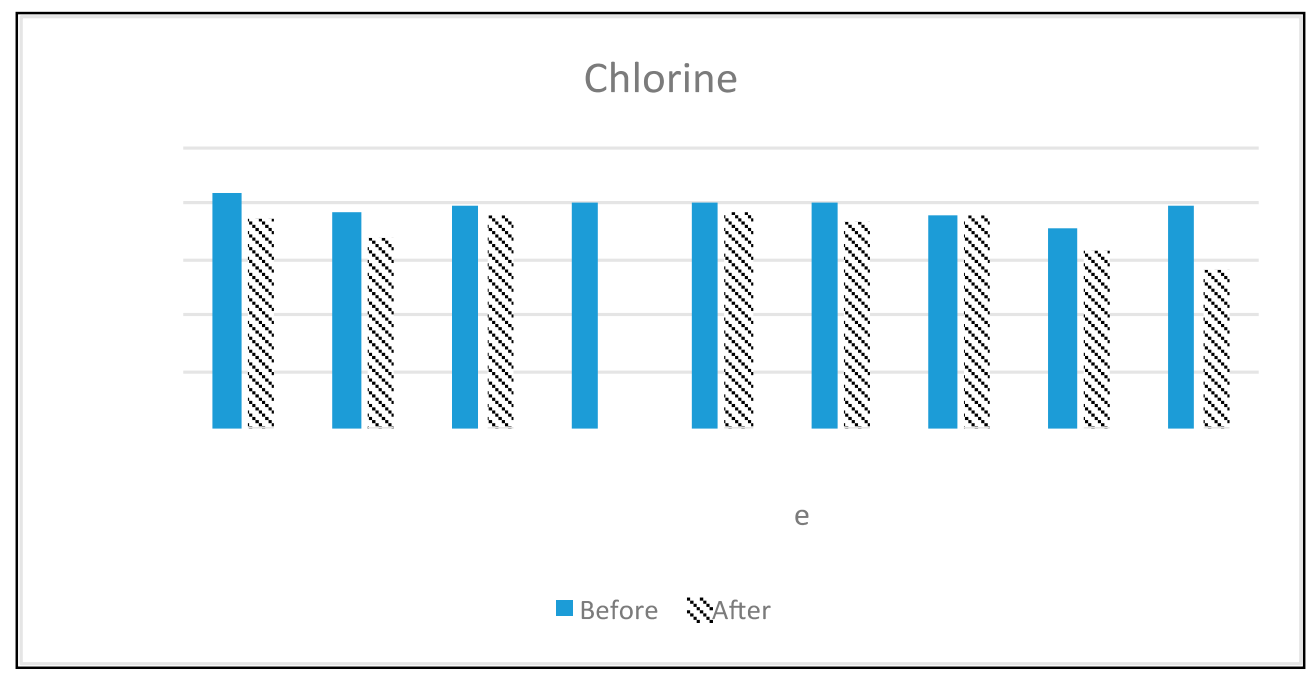

Figure 10. Results of chlorine content (mg/L).

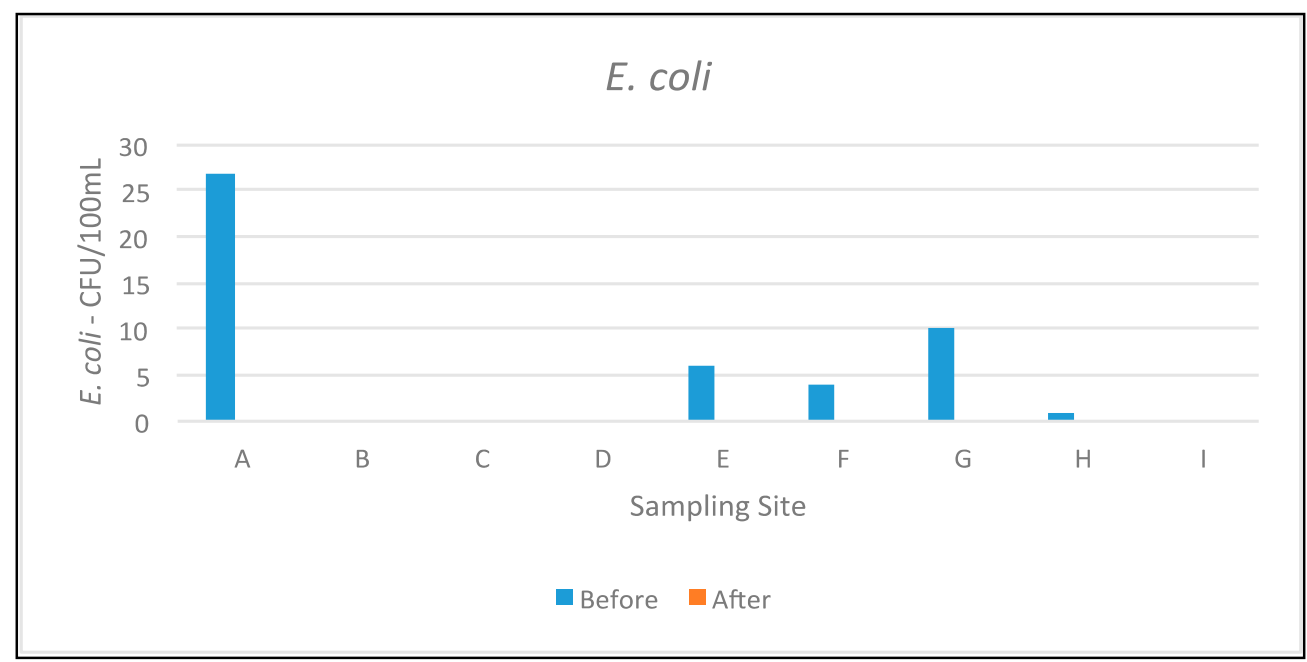

Figure 11. Results of $E$. coli (CFU/100 mL).

\section{DISCUSSION}

As more and more municipal governments are facing the need to replace their existing utility infrastructure such as drinking water pipelines, there is a conscious effort to adopt more sustainable construction technologies that reduce environmental impacts, reduce traffic disruptions, and improve productivity. This paper demonstrated the benefits of Horizontal Directional Drilling (HDD) compared to traditional open-cut construction using quantitative data reflecting reduction in airborne emissions and improved productivity.

Engineers should design urban utility infrastructure projects also considering qualitative measures such as public inconvenience (i.e., extra commuting time, pedestrian safety and mobility, etc.). Pedestrian safety and mobility are much higher during HDD installations because open-cut 
involves open trench excavation that is a potential safety hazard to the general public even with barriers and other imposed safety measures. Moreover, mobility is also reduced during traditional open-cut construction due to closure of an entire street to traffic for an extended period of time because of the excavation and street restoration requirements. Conversely, only half of a street was temporarily closed during the HDD installations in Yuma, thereby enabling continuous traffic flow in the neighborhood.

Landscape disruption is also an important qualitative measure to consider in sustainable construction. According to [10], landscape ecology is one of five perspectives on urban form. For example, HDD results in minimal, if any, disruption to landscape and vegetation. Open-cut more often results in removal of trees, plants and other natural surface features along the installation path. Environmental protection and resource conservation are imperative in sustainable construction.

This head-to-head comparison of traditional open-cut construction to HDD demonstrated the benefits of adopting trenchless technologies such as HDD. There has been an increase in the utilization of such technologies in the municipal arena over the past decade.

\section{CONCLUSIONS}

This paper described a field research study to capture and analyze site data comparing differences in environmental impacts, traffic impacts, and productivity between traditional open-cut construction and Horizontal Directional Drilling (HDD) during the pipe installation phase. Benefits of adopting of sustainable infrastructure development practices were captured in comparing environmental, social, and economical factors between the two installation methods. A case study involving a replacement project of existing asbestos-cement waterline in Yuma, Arizona was used to collect data for analysis. The project was unique in that it provided a head-to-head comparison of the two methods in the same local environment. The field study involved assessing the installation of 945 L.F. (288 m) of 6-inch (150 mm) C900, CL 235 DR18 fully restrained PVC water pipe using traditional open-cut construction and 1580 L.F. (482 m) of 6-inch (150 mm) C900, CL 235 DR18 fully restrained FPVC water pipe using HDD.

Field emissions data was collected and inputted into the eCalc ${ }^{\mathrm{TM}}$ software. The results found the HDD option to have emitted approximately $23 \%$ of airborne emissions compared to open-cut. Furthermore, converting emitted emissions to a normalize value found HDD to have produced less than a third of $\mathrm{CO}_{2}$ emissions in comparison, thereby demonstrating its environmental benefits.

As expected, traffic impacts were minimized with the HDD option. The sections with installations using traditional open-cut construction involved closure of the entire street to traffic because of the excavation requirements. Conversely, only half of the street was closed during the 
HDD installations, thereby enabling continuous traffic flow in the neighborhood. This resulted in minimal inconvenience to the local residents adhering to social benefits.

Overall productivity was much higher using the HDD option. The analysis found HDD achieved an average productivity of 1.91 L.F./min $(0.58 \mathrm{~m} / \mathrm{min})$ compared to traditional open-cut, which achieved an average productivity of 0.43 L.F./min $(0.13 \mathrm{~m} / \mathrm{min})$. This translates to HDD achieving productivity greater than four times that of open-cut, thereby demonstrating economic benefits. It is worth noting that surface restoration was not included in the analysis because the City of Yuma planned to repave all of the streets regardless of installation method. Adding surface restoration would have further demonstrated the higher productivity of HDD.

Water samples were initially taken on February 10, 2016 and then on July 29, 2016 once the system had been in operation for a few months. There was a slight to moderate reduction in chlorine content after installation of the new water lines. $E$. coli was present in five samples (hydrants) taken prior to replacement; however, post installation samples did not reveal any E. coli present. Overall, testing of these water samples further demonstrated the environmental importance of replacing aging drinking water lines to improve human health quality in a community.

Taking environmental, social and economical pillars of sustainability into account, traditional open-cut methods have adverse impacts on a community, business, and the traveling public due to undesirable pollution, traffic disruptions, and decreased productivity when compared to HDD. Replacement of aging drinking water lines should look at adopting technologies that foster sustainable urban development.

\section{DATA AVAILABILITY}

The dataset of the study is available from the authors upon reasonable request.

\section{AUTHOR CONTRIBUTIONS}

SA and NG designed the study. NG designed/engineered the project. SA performed and oversaw the field data collection and analysis. SA and NG wrote the paper.

\section{ACKNOWLEDGMENTS}

The authors would like to recognize the support of the City of Yuma, AZ for engaging in this study.

\section{CONFLICTS OF INTEREST}

The authors declare that there is no conflict of interest. 


\section{REFERENCES}

1. Yan X, Ariaratnam ST, Dong S, Zeng C. Horizontal Directional Drilling: Stateof-the-Art Review of Theory and Applications. Tunn Undergr Space Tech. 2018;72:162-73.

2. US EPA. Procedures for Preparing Emission Factor Documents. EPA/454/R95/015. Research Triangle Park (NC, US): US EPA, OAR; 1997.

3. Ariaratnam ST, Sihabuddin S. Comparison of Emitted Emissions between Trenchless Pipe Replacement and Open-Cut Utility Construction. J Green Build. 2009;4(2):126-40.

4. Matthews J, Selvakumar A, Ariaratnam ST. Evaluation of the Carbon Footprint of on Innovative Sewer Rehabilitation Methods. In: Proceedings of the 32nd International No-Dig Madrid Conference and Exhibition; 2014 Oct 13-15; Madrid, Spain. Dhaka (Bangladesh): ISTT; 2014. Paper 2B-3 on CD.

5. Sihabuddin S, Ariaratnam ST. Methodology for Estimating Emissions in Underground Utility Construction Operations. J Eng Des Tech. 2009;7(1):37-64.

6. Ariaratnam ST, Guercio N, Kim J, Panos X. Asbestos Cement Drinking Water Replacement at the City of Yuma, AZ: A Case Study. In: Proceedings of Pipelines 2017 Conference; 2017 Aug 6-9; Phoenix, AZ, US. Reston (VA, US): ASCE; 2017.

7. Tighe S, Less T, McKim R, Haas R. Traffic Delay Savings Associated with Trenchless Technology. J Infrastruct Syst. 1999;5(2):45-51.

8. Gilchrist A, Allouche E. Quantification of Social Costs Associated with Construction Projects: State-of-the-Art Review. Tunn Undergr Space Tech. 2005;20(1):89-104.

9. Gangavarapu BS, Najafi M, Salem O. Quantitative Analysis and Comparison of Traffic Disruption Using Open-Cut and Trenchless Methods of Pipe Installation. In: Proceedings of the ASCE International Conference on Pipeline Engineering and Construction, ASCE; 2003 Jul 13-16; Baltimore, MA, USA. Reston (VA, US): ASCE; 2003. doi: 10.1061/40690(2003)186

10. Clifton K, Ewing R, Knaap G-J, Song Y. Quantitative Analysis of Urban Form: A Multidisciplinary Review. J Urban. 2008;1(1):17-45.

How to cite this article:

Ariaratnam ST, Guercio N. Sustainable Replacement of Aging Drinking Water Lines Using Horizontal Directional Drilling Technology. J Sustain Res. 2020;2(3):e200028. https://doi.org/10.20900/jsr20200028 